\title{
Atlantis
}

Critical Studies in Gender, Culture \& Social Justice

Études critiques sur le genre, la culture, et la justice

\section{Dis/Consent: Persepectives on Sexual Consent and Sexual Violence}

\section{Johannah May Black}

Volume 41, Number 1, 2020

URI: https://id.erudit.org/iderudit/1074018ar

DOI: https://doi.org/10.7202/1074018ar

See table of contents

Publisher(s)

Mount Saint Vincent University

ISSN

1715-0698 (digital)

Explore this journal

Cite this review

Black, J. (2020). Review of [Dis/Consent: Persepectives on Sexual Consent and Sexual Violence]. Atlantis, 41(1), 82-84. https://doi.org/10.7202/1074018ar 


\section{Dis/Consent: Persepectives on Sexual Consent and Sexual Violence}

Johannah May Black currently works full time as the Bystander Program Coordinator at the Antigonish Women's Resource Centre \& Sexual Assault Services Association. She is the author of the Waves of Change Bystander Intervention Training Program which has been adopted at all of the Nova Scotian universities and the Nova Scotia Community College.

Book under review: Malinen, KelleyAnne, ed. 2019. Dis/Consent:Persepectives on Sexual Consent and Sexual Violence. Black Point: Fernwood Publishing.
Several books on the Canadian realities of rape cul$\checkmark$ ture and sexual violence have been released in the last four years (Busby and Birenbaum 2020; Craig 2018; Quinlan, Quinlan, Fogel, and Taylor 2017). KelleyAnne Malinen's (2019) Dis/Consent joins this important body of work by taking aim at the multifaceted ways that power and oppression are tangled up with rape culture, sexual violence, and erotophobia. The volume particularly excels in its fearless dive into the heart of the contradictions, messiness, and complexities of thinking through consent, survivor activism, agency, and autonomy typically absent in popular discourse surrounding sexualized violence and consent. The innovative title concept of dis/consent embraces this messiness and complexity and at the same time signals a politics of dissent and discontent. In the introduction to the volume Malinen argues:

The prefix 'dis' indicates a reversal or contrary force. 'Dis/Consent' can also be read as a critique of the notion of consent as it commonly presented in popular culture. Too often, consent is understood as a kind of currency, typically passed from women to men, in decontextualized exchanges. In reality, moments of consent or non-consent always occur in a social context, where power is at play. (8)

Here we find the clearly articulated point of departure from which the book re-introduces the very complexity, power relations, and context that are often flattened out or missing entirely in scholarly writing on the topic.

The book is inclusive of a wide range of perspectives, styles, methodologies, and politics embracing a democratic ethos that encourages the reader to be open to diverse and dissenting voices. By "wrapping" the volume in two chapters written by Mi'kmaw scholar Sherry Pictou, Malinen attempts to resist linear and colonialist conceptions of space/time by embracing cyclical thinking, to uncover "relationships of in- 
debtedness," and to enact a "standing together across communities" (10-11). Pictou's chapters are grounded in "Indigenous teachings and interpretations" (19). At a time when Indigenous women's leadership is breathing life into the global movements for planetary survival, Pictou's chapters offer critical insight into a praxis that moves beyond survival and into resurgence. While Malinen's decision to encircle the volume in an Indigenous worldview is novel and illuminating, one cannot help but wonder what it would be like if settler feminists were willing to extend more space in their scholarship and organizing in order to work through the implications of this colonial relationality. Settler feminists concerned with consent and sexual violence must endeavor to make clear and explicit links between broader rape culture and the colonial, capitalist judicial system which denies Indigenous peoples the rights to free, prior, and informed consent over development projects on their own territories. In the context of settler colonialism, the fight for the agency and autonomy of survivors and for other oppressed and marginalized peoples should be grounded in the struggle for Indigenous sovereignty. Malinen's book stops short of recognizing these broader connections.

The inner circle of content in the book is divided into two broader themes related to the overarching concept of Dis/Consent. Legislation, Policy, and Government; and Dis/Consenting Agents. For example, the clumsy engagement of the legal system with sexual violence is made apparent in Chapter 4, where the Mount Saint Vincent University (MSVU) Feminist Collective takes on the infamous Judge Lenehan decision in the alRawi sexual assault trial. The MSVU Feminist Collective asks: "What does this legal decision teach other men who view women as sexual objects and feel entitled to women's bodies?" (53). Then, in Chapter 6, Mandi Gray, Laura Pin, and Annelies Cooper elucidate the ways that so-called "student consultation" is used by post-secondary institutions responding to sexual violence on campus to "appease stakeholders without substantively addressing their concerns" (65). By delving into their experiences advocating for survivors during the creating of York University's government-mandated sexual violence policy, Gray, Pin, and Cooper argue that universities gain legitimacy for their policy decisions through processes of "student con- sultation." However, these same processes are often public relations exercises designed to manufacture consent for pre-written policies rather than genuine attempts at consultation made in good faith early enough in the process to gather and incorporate this feedback in any meaningful way. In this sense, students and survivors on campus are not positioned as knowledgeable subjects who can provide valuable input to the policy but rather as gate-keepers. This is similar to the feminized subject in traditional heterosexual scripts whose power is limited to the ability to grant or refuse the actions authored by the masculinized sexual actor.

The second half of this volume invites us to reimagine agency and autonomy for differently positioned survivor subjectivities. In Chapter 8, Malinen gives voice to survivors of "woman-to-woman sexual assault" (84). While in Chapter 9, Alan Santinele Martino advocates for the sexual decision-making rights of individuals with intellectual disabilities (98). Chapter 12, co-authored by activists, poets, and academics El Jones and Ardath Whynacht, is especially timely in the context of current activist movements denouncing police violence and advocating to defund the police. Jones and Whynacht welcome the reader into a dialogue on the "intersection of anti-rape activism and prison abolitionism” (142). Jones and Whynacht's discussion is instructive in its exploration of how a carceral response to harm does not allow us to "resist rape culture because it avoids social responsibility in favour of individual blame" (148). At the same time they acknowledge and affirm that "those who have experienced harm should be free to be angry, to be resentful, to never forgive if that doesn't feel right for them" (143). They powerfully assert: "Confronting sexual violence should be messy and disorienting, and we need to prioritize understanding lived experiences so that we can better our approaches to healing" (151). Jones and Whynacht's discussion is a welcome departure from liberal feminist approaches that rely upon rates of incarceration as "a measure of how seriously society takes sexual assault” (143).

This book offers a fresh perspective on the structural, cultural, and institutional frameworks of consent, demonstrating the conditions of possibility and impossibility that shape sexual autonomy for differently 
positioned agents in Canadian society. The book's biggest strength, the heterogenous texture and multiplicity of voices, is also its greatest weakness in failing to articulate a clear, over-arching theoretical framework. Without this framework to tie the diverse perspectives and approaches together, the reader may be left wondering: Where to go from here? However, there is plenty in this book to spark important conversations and transformative thought for many readers.

\section{References}

Busby, Karen and Joanna Birenbaum. 2020. Achieving Fairness: A Guide to Campus Sexual Violence Complaints. Toronto, ON: Thomson Reuters.

Craig, Elaine. 2018. Putting Trials on Trial: Sexual Assault and the Failure of the Legal Profession. Montreal, QC: McGill-Queens University Press.

Quinlan, Elizabeth, Andrea Quinlan, Curtis Fogel, and Gail Taylor. 2017. Sexual Violence at Canadian Universities: Activism, Institutional Responses, and Strategies for Change. Waterloo, ON: Wilfred Laurier University Press. 